\title{
DOSSIÊ CLITICIZAÇÃO
}




\section{DATIVO OU LOCATIVO? SOBRE SENTIDOS E FORMAS DO "DATIVO" NO PORTUGUÊS}

Rosane de Andrade Berlinck*

\section{Introdução}

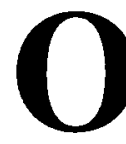

estatuto dos complementos verbais derivados, no português, do dativo hatino não constitui ainda uma questão definitivamente resolvida nas descrições da língua. Para ilustrar essa controvérsia, basta considerarmos, por exemplo, a posição de Cunha e Cintra (1985), que incluem esses complementos em um conjunto mais amplo de complementos preposicionados sob o rótulo geral de "objeto indireto" e aquela de Mateus et al. (1983), que prefere distinguir os complementos "dativos" dos demais complementos ligados indiretamente ao verbo, com base em suas características semânticas e formais particulares.

Uma classificação diferente aparece em Perini $(1989 ; 1995)$. Sua proposta de categorização das funções sintáticas identifica quatro funções relevantes ("aquelas que são exigidas ou então recusadas por algum verbo") no âmbito da transitividade: objeto direto, complemento de predicado, predicativo e adjunto circunstancial. O complemento "dativo" é incluído no grupo dos "adjun-

* Universidade Estadual Paulista - Araraquara. 
tos circunstanciais". Das quatro funções mencionadas, essa talvez seja a mais problemática, pois inclui, ainda, outros complementos preposicionados (como de Maria em "Mané apanhou de Maria") e também advérbios (como muito em "Juracy bebe muito").

Em todos esses casos, o complemento "dativo" é visto como um dos termos essenciais da oração ou aquele que realiza uma das funções sintáticas centrais na sentença ou ainda como uma das funções relevantes do ponto de vista da transitividade. Essa não é, porém, uma opinião unânime.

Dillinger (1991), partindo da proposta de Perini (1989), questiona a pertinência de se definir o objeto indireto como uma função sintática independente no português. Ele afirma que semanticamente o objeto indireto é interpretado como uma "localização", uma "orientação" ou uma "direção no espaço". No entanto, esse significado não está na relação estrutural; ele é definido pelas preposições que introduzem o complemento, assim como são as preposições que definem o valor semântico de SPs com função adverbial. Desse modo, não haveria como justificar uma categoria "objeto indireto" independente da categoria "adjunto adverbial". E conclui: "Se a relação estrutural fosse portadora de significado independentemente das preposiçōes, seria possível identificar algum elemento de significado comum a todos os casos da relação e que não estaria presente quando as preposições fossem usadas no contexto de outras relações estruturais", o que não ocorre, segundo ele.

Tendo essas idéias como pano de fundo, nossa proposta é discutir o estatuto do "objeto indireto" ou do "complemento dativo" em português, a partir de uma reflexão sobre alguns dados da história da expressão desse complemento.

\section{O dativo latino}

Nessa discussão, uma volta à fonte do "dativo" português - a língua latina - pode ser bastante reveladora. Nesse retorno, duas questões vão-nos ocupar: primeiramente, quais os sentidos veiculados pelo caso "dativo" em latim. Em seguida, como se deu a mudança na forma da expressão dos complementos que eram originariamente marcados pelo "dativo". Basearemos essa discussão inicial em Van Hoecke (1996).

Segundo Van Hoecke (1996, p. 6), a escolha do termo "dativo" (de dare) revela que para os gramáticos latinos o caso designado significava "atribuição", 
ou casus dandi. Ou seja, o dativo indicaria "a pessoa para quem algo é dado, dito, enviado, trazido".

No entanto, o autor também chama a atenção para o fato de que esse caso era empregado em um grande número de construções que não veiculavam propriamente esse significado. Esses outros sentidos incluíam as noçōes de "remoção", de "interesse", de "aproximação" e de "finalidade", como ilustram, respectivamente, as sentenças em (1a-d), emprestadas de Van Hoecke (1996, p.6-12):
(1) a. Caesar
scutum
militi
detraxit
César-NOM escudo-AC soldado-DAT tirou
"César tirou do soldado o escudo"
(Caesar, De Bello Gallico, 2,25)

b. Fortuna

favet fortibus

Sorte-NOM

favorece

bravos-DAT

"A sorte favorece os bravos"

(provérbio, cf. Lavency 1985b, p. 161)

c. Puer

adnatat

delphino

Criança-NOM aproximou nadando golfinho-DAT

"A criança nadou para o golfinho (até o golfinho)"

(Plinius, Epistulae, 9-33)

\section{d. Facundiam tuendis civibus exercebat.}

eloqüência-AC proteger-DAT GER compatriotas-DAT praticava "Ele praticava a eloqüência para proteger seus compatriotas" (Tacitus, Annales, 15-48)

Essa heterogeneidade semântica, nos diz o autor, é aparente, pois é possível identificar um sentido mais geral subjacente a essas realizações particulares. Van Hoecke designa esse sentido de "pólo de orientação". A idéia é de que o complemento marcado pelo caso dativo representa o pólo em direção ao qual o processo expresso na sentença é dirigido.

Esse sentido geral englobaria até mesmo construções sintaticamente diferenciadas como os dativos possessivus, sympatheticus, auctoris, iundicantis e ethicus, em que o complemento marcado pelo dativo não representa um argu- 
BERLINCK, R. Dativo ou locativo?...

mento do verbo, como ilustram, respectivamente, os exemplos em (2a-d), de Van Hoecke (1996, p. 13-17).
(2) a. Amplissimae
tibi
divitiae
sunt.
muito grandes-NOM
te-DAT
riquezas-NOM
são
"Muito grandes riquezas te estão à disposição"
(Cicero, In: M. Antonium orationes Philippicae, 10,4)

b. Iam tibi istam scelestam linguam abscindam.

Agora te-DAT essa criminosa língua-AC cortarfora

"Agora te vou cortar fora essa língua criminosa"

(Plautus, Amphitruo, p. 556)

c. Faciendum est mihi illud...quodillaec postulat. Fazer-NOM GER ser-3SG me-DAT que... o qual ela-NOM pede "Aquilo que ela pede deve ser feito por mim"

(Plautus, Amphitruo, p. 891)

d. Quintia

formosa

est multis.

Quintia-NOM

formosa-NOM é

muitos-DAT

"Para muitos Quintia é formosa"

(Catullus, 86, 1)

e. Alter

tibi

O outro-NOM

te-DAT

descendit

de

Palatio.

(Cicero, Pro Sexto Roscio Amerino, p. 133)

Os exemplos apresentados em (1) e (2) ilustram a expressão morfológica do "dativo" latino. Sabemos que esse recurso se perde aos poucos na língua falada, em associação com um processo fonético de redução de segmentos finais de palavras (Tarallo, 1990) e que isso está na base da expansão e gramaticalização do uso das preposições nas línguas românicas. A competição entre o caso morfológico e as preposições, porém, já existe em germe no próprio latim clássico. Consideremos o uso do verbo adducere ("conduzir") (3 ac): ${ }^{1}$

1 Os exemplos em (3) são de Van Hoecke (1996, p. 20). 
BERLINCK, R. Dativo ou locativo?...

(3) a.Hominem alicui adducere.

Pessoa-AC alguém-DAT conduzir

"Conduzir uma pessoa a alguém"

(Plautus, Mostellaria, p. 804)

b. Adducere exercitum ad urbem.

Conduzir exército-AC à cidade-AC

"Conduzir o exército à cidade"

(Cicero, In M. Antonium orationes Philippicae, 5, 22)

c. Adducere exercitum in fines.

Conduzir exército-AC no território-AC

"Conduzir o exército para dentro do território"

(Caesar, De Bello Gallico, 5, 46, 3)

Observamos em (3) uma distribuição complementar entre o uso do caso morfológico e as preposições: o primeiro se restringe ao complemento que se refere a pessoa; a preposição, por sua vez, é usada para indicar um lugar, com uma variação entre $\mathrm{AD}$ e IN, segundo se quisesse indicar "destino, deslocamento em direção a algum lugar, ou até suas proximidades" ( $3 b$ ) ou se se juntasse a esse significado o de interioridade (3c). A presença dessa alternância já em textos clássicos é reveladora. $\mathrm{O}$ uso de preposições com complementos que normalmente seriam marcados pelo ablativo refletia uma prática que deveria já estar bastante avançada na fala.

Um outro fato observado na língua falada revela a extensão já alcançada pela mudança na expressão do Dativo: a tendência a substituir o caso dativo por uma construção preposicionada com $\mathrm{AD}$, mesmo quando os nomes se referiam a uma pessoa ou a um nome abstrato sem conotação locativa (Van Hoecke,1996, p. 21), como vemos em (4a-b).

(4) a.Hunc ad carnificem dabo Esse-AC ao carrasco-AC entregarei "Entregarei esse homem ao carrasco" (Plautus, Captivi, p. 1019)

b. Ad hostes exuvias dabit Aos inimigos-AC as peles-AC deixarei "Deixarei as peles para os inimigos" (Plautus, Epidicus, p. 38) 
Temos ainda que considerar o uso preferencial da construção com AD junto ao verbo scribere, na fase clássica da língua, embora o dativo ainda fosse possível, como assinala Van Hoecke (1996, p. 21):

(5) a. Scribit

Labieno veniat.

Escreve Labieno-DAT vir-3SG SUBJ

"Ele escreve a Labieno para que venha"

(Caesar, De Bello Gallico, 5, 46, 4)

b. Scribes

ad me.

Escrever-2SG FUT a mim-AC

"Escreverás para mim"

(Cicero, Epistulae ad Atticum, 5, 4, 2)

Finalmente, para a expressão da "origem", o latim usava uma construção preposicionada geralmente seguida de ablativo (6). Essa possibilidade acaba se estendendo à expressão do sentido de "remoção", que, antes marcado pelo dativo (7), passa a se realizar como em (8):

(6) A Caesare redire.

De César-ABL voltar.

"Voltar de César"

(7) Caesarscutum militi detraxit.

César escudo-AC soldado-DAT tirou

(8) Caesar scutum a milite detraxit.

César escudo-AC ao soldado tirou

"César tirou do soldado o escudo"

Podemos concluir, a partir dos processos de variação na expressão do valor "dativo" em latim descritos acima, que houve desde cedo uma interferência entre os campos nocionais de dativo e de espaço. Essa interpenetração se explica e se justifica se assumirmos, juntamente com Van Hoecke (1996), que o sentido geral do dativo era de um "pólo de orientação do processo descrito". Vemos que entendido desse modo, o dativo se aproxima muito de um locativodirecional. Assim, a escolha da preposição AD para marcar o dativo, num momento em que o sistema casual começa a enfraquecer, é perfeitamente compreensível e previsível. 


\section{O Dativo no português}

Até que ponto o quadro descrito para o latim permaneceu em português? Seria possível e pertinente falarmos em uma categoria "Dativo" nessa língua? Ou seja, podemos identificar para os complementos verbais que eram marcados pelo caso "dativo" em latim um sentido geral que justifique definir o "Dativo" como uma relação estrutural distinta das demais no português, ao contrário do que defende Dillinger (1991)?

Para discutir essas questões propomos considerar a variação e a mudança no uso da preposição em complementos com uma interpretação de "meta" no português brasileiro, do século XIX até hoje.

\section{A preposição de complementos com valor "meta" no PB}

Vamos encontrar o valor "meta" em português tanto em complementos oblíquos com valor locativo-direcional, quanto em alguns daqueles que estamos chamando de dativos. A análise da realização dessa noção semântica mostra-se, portanto, particularmente interessante para a discussão do sentido veiculado pelos "dativos" e dos limites que existem (se realmente existem) entre as noções "Dativo" e "Locativo" em português.

A análise de dados oriundos de anúncios de jornais paulistas ${ }^{2}$ e de peças teatrais do século XIX revela que a "meta" podia ser marcada variavelmente por diversas preposições naquele momento. Os exemplos em (9-11) ilustram essas alternâncias:

(9) a. Quem quizer comprar um armazem de molhados, dirija-se NA RUA DO ROZÁRIo Casa n. 33, onde achara com quem tractar o negócio.

b. Pede a quem souber onde ella existe, dirija-se À RUA DO ROSÁRIO na casa n. 29, que sendo viridica a noticia receberá boas alviçaras.

(Farol Paulistano, 1829)

(10) a. Meus senhores, só vejo um modo de conciliar esta contenda, que é darem os senhores este leitão de presente a ALGUMA PESSOA.

(O Juiz de Paz na Roça, M. Pena, 1833)

2 Os anúncios que serviram de fonte para esses dados fazem parte do primeiro 
b. A quem o apprehender e entregar NA FAZENDA DO ABAIXO ASSINADO dar-se-ha 400\$000. (O Correio Paulistano, 27/7/1879)

(11) “- Sinhozinho! Mimoso! Diga a mamāe que eu estou aqui... - Pra MAMĀE eu digo; mas PRA TITIA não digo, não!"

(A Viúva Pitorra, S. Lopes, 1896)

Três tipos de predicadores, diferentes em sua natureza semântica, se destacam nesses exemplos. Vamos chamá-los, respectivamente, de verbos de movimento (9), verbos de transferência material (10) e verbos de transferência verbal/perceptual (11) (cf. Berlinck, 1996a). Nossa análise mostra que as preposições introdutoras de complementos não variam do mesmo modo segundo tenhamos um ou outro verbo.

A figura 1 traz os resultados obtidos para os verbos de movimento. ${ }^{3}$ Dois fatos chamam imediatamente a atenção: primeiramente a presença das três preposições, embora em proporções bastante diversas; em segundo lugar, um contraste bem marcado entre os dados oriundos das comédias e aqueles colhidos nos anúncios de jornais.

Preposições em SPs "meta" com verbos de movimento

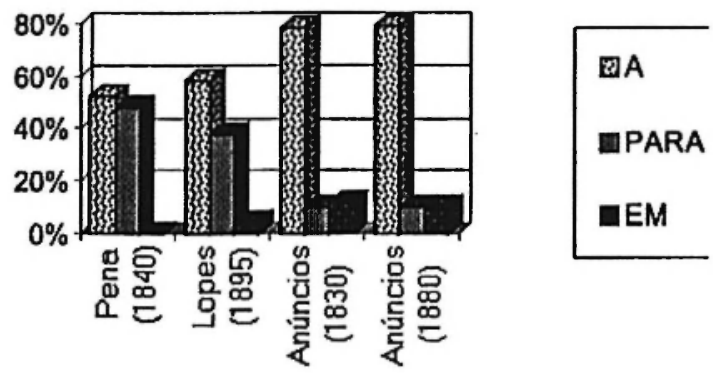

Figura 1

volume do corpus do projeto "Para a história do português brasileiro" (Guedes e Berlinck, 2000).

3 Apenas os verbos que apresentaram variação na composição de seus complementos forma incluídos na análise. Assim, as ocorrências de entrar, fugir, parrir e seguir não foram computadas, já que o primeiro aparece sempre com a preposição em e os demais só ocorrem com para. 
Uma volta aos dados revelou que essa disparidade poderia ser explicada, em parte, pelo fato de que metade dos casos de verbo de movimento encontrados nos anúncios corresponde a ocorrências de um único verbo - DIRIGIR-SE. Este aparece em mais de $80 \%$ das vezes com a preposição "a", como no exemplo abaixo:

(12) "Acabam de chegar da Allemanha e desejam empregar-se, aqui ou em outra qualquer parte, 2 Padeiros 2 Caixeiros 1 Serrador 7 Mineiros os quais não duvidam aceitar outro qualquer que lhe ofereça. Quem do seu préstimo quizer utilizar-se DIRIJA-SE Ao CONSULADO, Rua de S. Bento n. 53"

(Correio Paulistano, 27/7/1879)

Os demais anúncios em que a referida construção foi observada seguem basicamente o padrão desse em (12), o que nos leva a pensar em uma estrutura relativamente cristalizada, uma fórmula própria desse tipo de texto.

Também com os verbos de transferência material há grande variação entre preposiçōes, como mostra a figura 2. Aqui, porém, cada sub-corpus apresenta uma distribuição diferente das preposiçōes.

Preposições em SPs "meta" com verbos de transferência material

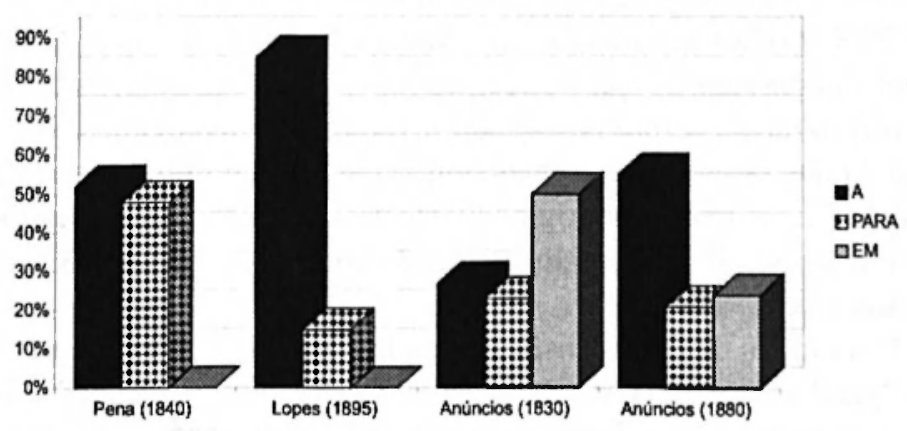

Figura 2

Em contraste com essas duas classes, os verbos de transferência verbal/perceptual apresentam um quadro quase isento de variação (figura 3 ). 
BERLINCK, R. Dativo ou locativo?...

Preposições em SPs "meta" com verbos de transferência verbal/ perceptual

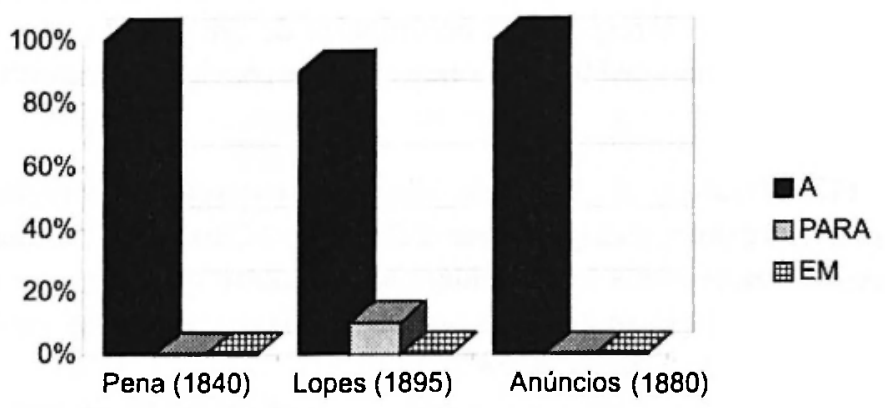

Figura 3

Que conclusão tirar das diferenças observadas entre os três tipos de verbos? Se considerarmos que a preposição que o português herdou do latim para a expressão do dativo foi o "a", o uso dessa preposição face a outras alternativas indica uma escolha mais conservadora, caso verificado com os verbos de transferência verbal/perceptual. Por outro lado, a opção por "para", especialmente, denotaria uma tendência inovadora.

A distribuição variável de preposições e, principalmente, a presença significativa das preposições "para" e "em", constatadas junto aos verbos de movimento e aos verbos de transferência material desde os textos do início do século XIX revela um caminho de mudança bastante definido. Esses verbos denotam, em sua significação básica, um movimento concreto, físico. Já os verbos de transferência verbal/perceptual se referem a um movimento metafórico, abstrato. O que estamos observando então é o mesmo tipo de percurso observado em latim: um marcador originalmente usado para indicar um deslocamento concreto tem seu uso expandido, atingindo contextos em que passa a denotar um "deslocamento abstrato".

Um indício dessa expansão nos dados do século XIX está nas ocorrências de "para" com verbos de transferência verbal/perceptual nas comédias de Simões Lopes, que datam do fim do século XIX. Se levarmos em conta que, no PB moderno, "para" é a preposição predominante na ex pressão da "Meta" com esses verbos (cf. Berlinck, 1997, 1998), os dados de Lopes estariam indicando um processo talvez em estágio inicial na fala. Nesse sentido, é interessante observar que essas ocorrências se dão pela voz de uma criança, contrastando claramente com a fala do adulto, como se vê abaixo: 
(13) - Sinhozinho! Mimoso! Diga a mamãe que eu estou aqui...

- Pra mamãe eu digo; mas PRA titia não digo, não!

(A Viúva Pitorra, S. Lopes, 1896)

Para refinar essa primeira constatação, analisamos os dados segundo o caráter [ \pm concreto] do movimento significado. Essa interpretação depende não apenas do tipo de verbo presente, mas, pelo menos, também da natureza do $\mathrm{N}$. Se a presença da preposição " $a$ " seguiu, de fato, o mesmo percurso de expansão de uso e significados observado na história das preposições (do mais concreto para o abstrato), deveríamos esperar que ela estivesse relativamente mais presente nas construções em que o movimento significado fosse [-concreto], metafórico, e vice-versa. Essa hipótese, efetivamente, foi comprovada pelos dados.

Com verbos de transferência verbal perceptual a noção de movimento é sempre metafórica. O predomínio da preposição "a" nesse caso pode então ser visto como uma decorrência da natureza do movimento significado, em consonância com a hipótese examinada.

Os resultados obtidos para as demais classes de verbos vieram reforçar esse primeiro: só foi registrada variação entre as preposições quando o movimento significado era concreto, físico (14); quando se tratava de um movimento abstrato, metafórico, apenas a preposição "a" apareceu (15).

(14) a. (...) chegando À LoJA não esqueça, não vá me deixar em falta;

(A Viúva Pitorra, S. Lopes, 1896)

b. Vim para aqui convicta de que vinha PARA A CASA DELE, nossa casa.

(Por causa das bichas, S. Lopes, 1896)

c. A mamãe foi nA Modista. A titia já vem.

(A Viúva Pitorra, S. Lopes, 1896)

(15) a. Desgraçadamente ainda não pagamos suficiente tributo AOS PRECONCEITOS DA SOCIEDADE! (Nossos Filhos, S. Lopes, 1896)

b. Assim não estranhará quando chegar $\grave{A}$ IDADE DE ENTRAR NO CONVENTO; será frade feliz. (O Noviço, M. Pena, 1833)

Para representar a extensão desse contraste, a figura 4 apresenta em conjunto os resultados da análise de verbos de transferência material, segundo essa oposição. 
BERLINCK, R. Dativo ou locativo?...

Variação de preposições segundo o caráter [+--concreto] do movimento

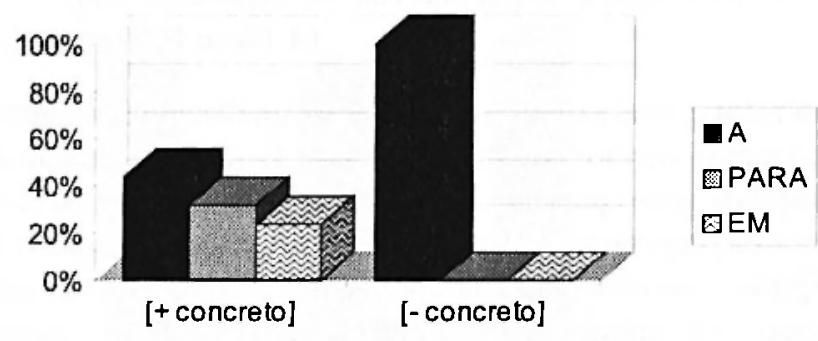

Figura 4

A análise dos dados oitocentistas revela ainda outros pontos de contato com os processos descritos para o latim na seção "O dativo latino". Ao avaliarmos uma possível correlação entre o caráter [ \pm animado] do $\mathrm{N}$ que compõe o complemento e a variação da preposição que o encabeça, observamos o seguinte quadro: por um lado, uma forte associação entre o traço [humano] e a preposição "a "; por outro, uma grande variação de preposições quando o $\mathrm{N}$ era [nãoanimado]. ${ }^{4}$

O quadro abaixo sintetiza os resultados obtidos na análise dos dados do século XIX.

\begin{tabular}{l|c|c} 
movimento [- concreto] & $\begin{array}{c}\text { N humano } \\
\text { N não-animado }\end{array}$ & preposção A \\
movimento [+ concret] & N humano & \\
N não-animado & preposiçōes A, PARA ou EM
\end{tabular}

O estudo revelou, confirmando a hipótese inicial, que o espaço da variação está circunscrito aos contextos em que o movimento significado é [+ concreto]. Nesse segmento, porém, as variantes não se alternam indistintamente. Embora possam-se combinar tanto com Ns humanos como não-animados, observou-se uma tendência à associar a preposição "a" ao traço [humano], reser-

4 Aplicada aos complementos das três classes de verbos, a propriedade só se mostrou pertinente para os complementos de verbos de transferência material. Com os verbos de movimento, cerca de $95 \%$ dos Ns que compõem o complemento são [não-animado]. Já com os verbos de transferência verbal/ perceptual, em $90 \%$ dos casos, o $\mathrm{N}$ é [humano]. Uma tal polarização revela que as distinçōes não são relevantes para a variação que está sendo analisada. 
vando as outras duas para a expressão do traço [não-animado]. Estaríamos, então, diante de uma tendência a distribuir complementarmente as variantes.

Observemos os seguintes dados:

(16) "quem o aprehender e entregar A SEU SENHOR, ou AOS SENHORES Lengruber MetTran \& Companhia à rua de São Pedro número 1 , no Rio de Janeiro, será gratificado com 200\$000, e EM QUALQUER CADEIA ou dando signaes certos, com $100 \$ 000 "$

(Correio Paulistano, 12/11/1879)

(17) "Aqui está o recruta; queira levar PARA A CIDADE. Deixe-o no quartel do Campo de Santana e vá levar esta parte aO GENERAL."

(Juiz de Paz na Roça, M. Pena, 1833)

É possível identificar uma especialização da noção de meta, em três nuances associadas, preferencialmente, com uma preposição distinta:

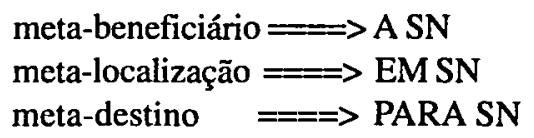

Com a crescente diminuição no uso do "a", constatada nos estudos relativos ao PB moderno (cf. Pontes, 1992; Mollica, 1996; Malvar, 1996; Berlinck, 1996b, 1997, 1998), a situação de variação deve ter se resolvido com a manutenção de "em" para indicar a meta-localização (e destino) e o uso cada vez mais significativo de "para", marcando a meta-beneficiário, como ilustram os dados em (18) e (19).

(18) a. "A BBC levou um número muito grande de pessoas NA PRAÇA" (locutor de rádio, 13/10/99)

b. Por que que o jovem não pode trazer NO MOVIMENTO ESPÍRITA a sexualidade dele?

(homem, 35 anos, nível superior, 1987)

c. "Depois de um passeio aqui a gente começa a da(r) importância NA PRESERVAÇÃO DA NATUREZA"

(homem, 30 anos, nível superior, 1999) 
(19) a. "A Mônica está tão triste desde que o coelhinho dela sumiu! Já sei!

Podemos levar bombons ou flores PRA ELA!"

(Cebolinha, 6 anos, história em quadrinhos infantil)

b. "porque nós demos uma imagem de santo PRO MEU PAI"

(mulher, 25 anos, universitária, 1987)

Para a expressão do movimento [- concreto], porém, a preposição "a" ainda constitui uma opção possível, como vemos em (20).

(20) "Tenho de entregar o perdão AO POvo."

(agricultor de Sobral, Ceará, 56 anos, 16/4/2000)

\section{Atando as pontas: existe um "Dativo" português?}

O que podemos concluir dessa viagem pela expressão do dativo em latim e em momentos recentes da história do português?

Vimos que a categoria dativo sofreu inúmeras mudanças na forma como é expressa tanto em latim, como em português e que essas mudanças seguiram os mesmos princípios nas duas línguas. Tratou-se de uma passagem de uma marcação morfológica para uma sintática e de variações dentro dessa última estratégia. Esse caminho se fez num sentido bem definido, iniciando em contextos em que o movimento significado é concreto e expandindo-se para aqueles em que se significa um movimento abstrato.

Outro aspecto interessante nesse processo é o fato de a língua ter, de um modo geral, sempre garantido uma distinção entre Ns "pessoa" e Ns "nãopessoa", como vemos resumidamente no quadro a seguir: ${ }^{5}$

5 As formas de expressão indicadas não esgotam as possibilidades de expressão do dativo nessas variedades. No latim falado, por exemplo, o uso de AD com pessoa era uma tendência em expansão, o que não eliminava a possibilidade de uso do caso morfológico. Também temos que considerar no português a possibilidade de expressar o dativo anafórico por meio de um pronome clítico, particularmente produtiva com referências de primeira e segunda pessoas até mesmo na variedade moderna. 


\section{Lingua}

Latim clíssico

Latim falado

PB - sćculo XIX

PB - século XX
Forma de expressāo

Caso morfobógico

Sprep com AD

Sprep com AD

Sprep com AD/IN

Spreb com A

Spreb com Para

Sprcb com EM

Spreb com PARA

Sprep com EM
Restrição scmântica do

N

Pessoa

Nāo pessoa

Pessoa

Nāo pessoa

Pcssoa

Não-pessoa (destino)

Não-pessoa (bocalizaçāo)

Pessoa

Nāo-pessoa

(localizaçāo/destino)

Apesar das mudanças acentuadas na forma de expressão dessa categoria, percebemos, porém, que, com poucas exceções, ${ }^{6}$ os mesmos contextos marcados com o caso dativo em latim são marcados com suas variantes modernas no português. Podemos identificar nas construções portuguesas o mesmo sentido geral apontado por Van Hoecke para o latim - o de um "pólo de orientação do processo descrito".

Ao contrário de Dillinger (1991), então, podemos pensar em uma categoria "dativo" para o português, que, do nosso tempo de vista, estaria subordinada a uma categoria mais ampla que também incluiria a categoria "locativo". $O$ fato de o "dativo" se realizar no português atual por meio de SPreps introduzidos por preposições que também encabeçam complementos locativo-direcionais se explica, assim, por esse parentesco nocional entre as duas categorias. Foi justamente esse parentesco que, quando do processo de substituição de casos por preposições no latim falado, determinou a adoção de uma preposição locativa - AD - para marcar o sentido do dativo. Quanto ao termo "objeto indireto", ele aponta para uma das formas de expressão do dativo (e de outras categorias), e não para sua natureza semântica.

6 Pensamos aqui no dativus auctoris, que indicava um agente da passiva e no dativo de finalidade (v. seção "dativo latino"). 
BERLINCK, R. Dativo ou locativo?...

\section{RESUMO}

Discute-se a pertinência de propor o dativo como uma categoria distinta em português. Comparando-se a expressão e os sentidos veiculados pelo dativo em latim e no português brasileiro, conclui-se que os mesmos princípios gerais regem seu uso em ambos os momentos, o que reforça a idéia de um dativo português.

Palavras-chave: Dativo, locativo, objeto indireto, caso, diacronia, língua portuguesa.

\section{ABSTRACT}

This text discusses the status of dative in Portuguese. By comparing the expression and the meanings conveyed by it in Latin and in Portuguese, we conclude that the same general principles govern its use in both moments. This reinforces the idea of dative as a distinct category in Portuguese.

Key-words: Dative, indirect object, case, diachrony, portuguese.

\section{REFERÊNCIAS}

A INTERPRETAÇÃO do objeto indireto em português. In: SEMINÁRIO DO GEL, 39., 1991, Franca. Anais... Franca: Unifran, 1991. p. 410-417.

ALI, M. S. (1964). Gramática histórica da língua portuguesa. 6. ed. São Paulo: Melhoramentos.

BERLINCK, R. A.(1996a). The Portuguese dative. In: VANBELLE, N.; VAN LANGENDONCK, N. (Ed.). Case and grammatical relations across languages. The dative. v. 1. Descriptive Studies. Amsterdam/Philadelphia: John Benjamins. 
(1996b). A expressão do objeto indireto no português do Brasil. In: SEMINÁRIO DO CELLIP (CENTRO DE ESTUDOS LINGÜÍSTICOS E LITERÁRIOS DO PARANÁ), 10., 1996, Londrina. Anais... Londrina: [s. n.], 1996.

. (1997) Sobre a realização do objeto indireto no português do Brasil. In: ENCONTRO DO CÍRCULO DE ESTUDOS LINGÜÍSTICOS DO SUL - CELSUL, 2., 1997, Florianópolis. Anais... Florianópolis: [s. n.], 1997.

(1998). Relatório final de atividades relativas a 'Bolsa de Recém-Doutor'. CNPq.

CÂMARA JÚNIOR, J. M. (1985). História e estrutura da língua portuguesa. Rio de Janeiro: Padrão.

DAMASCENO, D. (Ed.) (1956). Teatro de Martins Pena. v. 1: Comédias. Rio de Janeiro: Instituto Nacional do Livro.

GUEDES, M.; BERLINCK, R. de A.(Orgs.). (2000). E os prefos eram comodos... Anúncios de jornais paulistas do século XIX. São Paulo: Humanitas.

LOPES NETO, S. (1990). O teatro de Simões Lopes Neto. v. 1. Porto Alegre: Instituto Estadual do Livro.

MALVAR, E. (1996). Preposition usage with two verbs of motion in Brazilian Portuguese. Ms.

MATEUS, M. H. M. et al. (1983). Gramática da língua portuguesa. Coimbra: Livraria Almedina.

MOLLICA, M. C. M. (1996). A regência variável do verbo ir de movimento. In: OLIVEIRA e SILVA, G. M.; SCHERRE, M. M. P. (1996). Padrões sociolingüísticos. Rio de Janeiro: Tempo Brasileiro.

PERINI, M. (1995). Gramática descritiva do português. São Paulo: Ática.

PONTES, E. (1992). Espaço e tempo na língua portuguesa. Campinas: Pontes.

TARALLO, F. (1990). Tempos lingüisticos. Itinerário histórico da língua portuguesa. São Paulo: Ática.

VAN HOECKE, W. (1996). The latin dative. In: VAN BELLE, W.; VAN LANGENDONCK, W. (1996). The dative. v. 1: Descriptive studies. Amsterdam: John Benjamins. p. 3-37. 